Article

\title{
Academic Integration of Mainland Chinese Students in Germany
}

\author{
Hanwei $\mathrm{Li}^{1,2}$ \\ ${ }^{1}$ Faculty of Education, University of Tampere, 33100 Tampere, Finland; E-Mail: hanwei.li@staff.uta.fi \\ 2 Bielefeld Graduate School in History and Sociology, University of Bielefeld, 33615 Bielefeld, Germany
}

Submitted: 15 November 2016 | Accepted: 27 February 2017 | Published: 28 March 2017

\begin{abstract}
This article presents an analysis of the academic integration experiences of mainland Chinese tertiary-level students in Germany. Using Tinto's model, the article explores the challenges that Chinese students face during their academic integration, the strategies they employ, and the relationship between academic and social integration. The data were collected in spring 2016 by interviewing 26 mainland Chinese students studying either in German universities or universities of applied sciences. Four major challenges were identified and analyzed: language barrier, knowledge gap, pedagogical differences, and cultural differences. An important outcome of the study presented is that social integration serves as a facilitator for enhancing academic integration, but is not a prerequisite for academic success. Group learning with peers was found to enhance learning outcomes. Overall, Chinese students have exploited their own advantages in academic integration by exploring feasible strategies and benefiting from their past learning experiences. It is suggested that academic integration as a long and challenging process for international students should be acknowledged by the German HEls, and that more institutional support and guidance are needed.
\end{abstract}

\section{Keywords}

academic integration; Chinese student; Germany; higher education; social integration

\section{Issue}

This article is part of the issue "International Migration and Ethnic Integration", edited by Yaojun Li (University of Manchester, UK) and Anthony Heath (University of Oxford, UK).

(C) 2017 by the author; licensee Cogitatio (Lisbon, Portugal). This article is licensed under a Creative Commons Attribution 4.0 International License (CC BY).

\section{Introduction}

While the migration studies literature generally focuses on the integration of labor migrants, family migrants, and asylum seekers, there is less research focusing on the integration of international students. This is partly because international student mobility is often seen as 'temporary', and international students constitute a 'less problematic' group of foreign arrivals. However, the number of students pursuing studies abroad continues to surge as higher education institutions around the world compete for the most talented students, and university enrolment continues to increase worldwide. International students have become the key target of many countries' battlefields of global competition for brightest and best. Canada, for example, has recently changed its electronic immigration selection system to make it easier for international students to become citizens. It counts half of students' time spent studying in Canada toward the period of residence required for citizenship (Smith, 2017). Meanwhile, many European countries, such as Germany, France, the Netherlands, and Finland, have also pursued a policy of allowing international university graduates an extension to their residence permits for job seeking after graduation. International students are no longer classed as 'temporary migrants', rather it is hoped that their stay in the host country will increase motivation for long-term settlement, and that their temporary movement could be part of a deliberate strategy for permanent migration (Tremblay, 2005). Thus, integration of international students has become topical and deserves more scholarly attention.

Nevertheless, international students still only constitute a minority of the total tertiary student population. Chinese students are the most numerous of the international tertiary-level students (UNESCO Institute for Statis- 
tics, 2016). In 2013, over 4.1 million Chinese were studying abroad, representing 1.8 percent of all tertiary enrolments globally (UNESCO Institute for Statistics, 2016). Between the introduction of Deng Xiaoping's opening policy in the 1970s and 2015, around four million Chinese students went abroad to study, and this figure increases by approximately 19 percent annually. In 2016, about 520,000 Chinese students moved to study abroad (Ministry of Education of P. R. of China, 2016).

Chinese student migration mostly aims at the Englishspeaking countries (Chen \& Ross, 2015; Gu \& Schweisfurth, 2006; Kajanus, 2016), while Germany is the most popular destination among the non-English-speaking countries. According to the Institute of International Education, about 30,511 Chinese students were studying in Germany in 2015, making them the second largest group of international students in Germany (after Turkish students). The share of Chinese students of the international student population in Germany is around ten percent (Wissenschaft Weltoffen, 2016). Although most degree programs are still offered in German language (Bessey, 2012), Germany has become an increasingly popular choice for higher education among Chinese students.

Germany is a popular destination among Chinese students for several reasons. First, it is one of the few countries to offer all nationalities high quality higher education free of charge or for modest tuition fees, which is a major attractive factor for international students. Both English- and German-taught programs are provided for international students. Unlike many nonEnglish-speaking countries that are recruiting international students for English-taught programs, most international students study on German-taught programs alongside native German students. German language is taught in universities across the globe and language institutes such as the Goethe Institut. Germany also arranges established standardized German language tests (DSH and TestDaF) in many countries in the world, where students can obtain a language certificate in support of their applications for studies in Germany. For those students who cannot reach the requirement to begin their academic studies in Germany, it is possible to start the studies in the Studienkollegs (Studienkolleg für ausländische Studierende) at German colleges and universities. These studies function as a 'bridge' to help international students enhance their German language skills, and become acquainted with German academic culture. Further, Germany has an organization specialized in promoting academic mobility between Germany and other countries. The German Academic Exchange Service DAAD (Deutscher Akademischer Austauschdienst) offers information on studying in Germany, on selecting a university, on admission criteria, and on preparing to embark on studies in Germany. It also offers various types of scholarships to students across the globe for exchange, studying German language, or studying on degree programs. The DAAD has offices in many countries of the world, in- cluding China, that actively offer information on how to apply to study in Germany, and on academic collaboration and mobility. For example, in China the DAAD has its own social network accounts on WeChat and Weibo that routinely distribute information on the application process for studying in Germany, presents introductions to specific German universities and cities, and reproduces testimonials from current students.

In addition, Germany is one of the first countries in the EU to actively seek to improve international students' access to the labor market. In the context of the recent political debate, international students were identified as future skilled workers. The aim was to make access to the labor market easier for them, especially in the information technology sector. International graduates holding a degree from a German university are in a favorable position for getting job offers. Moreover, due to their linguistic skills and intercultural communication skills, international students can serve as 'connectors' between their countries of origin and destination. The latter factor is particularly relevant for the export-oriented German economy (Aksakal \& Schmidt-Verkerk, 2014).

Given this policy context, there has been growing concern over the extent to which German higher education institutions (HEls) manage to provide appropriate and responsive academic and personal support for the integration of international students. While numerous surveys have examined the macro-level trends in student mobility and the quality of German HEls, less attention has been paid to the experiences of individual international students.

The purpose of this paper is to investigate how Chinese students integrate into German academic environments, what challenges they encounter while studying in Germany, and what coping strategies they adopt for such challenges. The following research questions guided the study presented here: (1) what challenges do mainland Chinese students encounter while studying and living in Germany? (2) What strategies do Chinese students use to overcome challenges in their academic integration? and (3) Is there a connection between academic and social integration among Chinese students studying in Germany?

\section{Integration of International Students: The Research Context}

In earlier research on the academic and social integration and study progress of international students in a foreign academic setting, the terms 'integration', 'adaptation', and 'acculturation' have been used interchangeably in different settings, carrying largely similar connotations. This article chooses to use the term 'integration' because integration can be seen both as a goal and a process. When it comes to social relations, the goal of the German integration policy is that foreign newcomers will establish a relatively robust relationship with the host community, while not abandoning their home ethnic community and ethnic identity (Süssmuth, 2009). As 
a goal integration refers a situation in which newcomers have attained at least a moderate level of language and cultural competence within the country of settlement that ensures their ability to thrive. It also implies that migrants actively try to become a part of the surrounding society (Budyta-Budzyńska, 2011). It can be said that a successful adaptation presupposes that newcomers integrate into their new living environments, which in turn is usually a result of a successful acculturation process.

\subsection{Academic and Social Integration}

Tinto $(1975,1997)$ developed a model of student attrition that laid a theoretical foundation for studying tertiary student retention. In his model, Tinto established the approximate parity between social and academic integration in their effects on dropout. The central concept proposed in Tinto's model is that a student's integration into the social and academic systems of the higher education institution is what ultimately results in perseverance or dropout. The higher the degree of integration of the students into the college system, the less likely they are to fail to fulfill a commitment and achieve goals leading to the completion of their degree programs. A person's academic integration can be measured in terms of the grade performance and intellectual development achieved during studies. While international students enter university with various backgrounds and motivations, their integration into the higher education system will ultimately determine their perseverance or dropout. Tinto describes two imperative conditions for successful retention: (1) institutional experiences (involving the education system); and ( 2 ) academic and social integration. Those who feel at home, participate actively in extra-curricular activities, and feel connected with fellow students and teachers are more likely to persevere in their studies.

The predictive validity of Tinto's model was tested in various settings. One study suggested that students' academic integration, together with educational objectives, predicts their persistence in the HEls (Bers \& Smith, 1991). In addition to formal studies, informal interaction with faculty members plays a vital role in the students' academic integration (Terenzini \& Pascarella, 1977). However, Tinto's model does not specify the process by which institutional experiences affect student learning. While student characteristics prior to entry may affect their academic integration, the institutional experience results in a certain study effort and ultimately in student persistence. A study by Severiens and Schmidt (2009) examining institutional experiences of student learning, found a direct positive effect of the learning environment on international students' progress in their studies. A problem-based learning environment, more than conventional programs, helped students to develop their cognitive skills and stimulated them to acquire new knowledge. Problem-based learning also appeared to be successful in stimulating students to obtain credits, and achieve a higher level of social and academic integration.
One of the key themes among the studies using Tinto's model is the relationship between academic and social integration. The findings of Mannan (2007) show that academic and social integration complement each other among undergraduates. However, Rienties, Beausaert, Grohnert, Niemantsverdriet and Kommers (2012), who examined the validity of educators' impressions, found that international students are insufficiently adjusted to higher education in their host countries, both academically and socially, and that the extent of their academic success is multifaceted. International students with a (mixed) western background were better academically and socially integrated, and achieved a higher study performance than did domestic students. By contrast, international students with a non-western background were less socially integrated, but still achieved a similar study performance. The social adjustment of students was negatively related to their study performance. These findings suggest that the relationship between academic and social integration processes is complex in nature and merits further investigation.

Research on the social integration of international students has particularly emphasized the positive effect of establishing social networks with host nationals (Bochner, McLeod, \& Lin, 1977a; Coles \& Swami, 2012). Research has also shown that international students report less homesickness, less loneliness, and greater satisfaction if they have more host-national friends (Church, 1982; Hendrickson, Rosen, \& Aune, 2011). Contacts with host nationals have also been shown to enable international students to develop local networks, attain a better understanding of local cultures, and acquire the necessary social skills (Li \& Gasser, 2005). Yet in practice it may be difficult to make contacts with host-nationals. It is relatively easy for international students to form friendship networks with co-national students (Bochner, McLeod, \& Lin, 1977b; Furnham \& Alibhai, 1985; Hendrickson et al., 2011). While contact with co-nationals can play a vital role in the international students' social networks, engagement with co-nationals may inhibit them from forming friendship networks with representatives of the host society (Church, 1982), and from acquiring or improving skills in the host language (Maundeni, 2001), which impedes intercultural learning processes (Kim, 2000). Accordingly, Kim (2000) argues that co-national contacts only offer short-term support, while contacts and friendships with host-nationals are more important for social integration.

\subsection{Chinese Learners in Western Higher Education}

Studies focusing on the academic integration of Chinese students in western HEls have produced mixed and sometimes contradictory results. Kennedy (2002) found that Chinese culture has an influence on Chinese students' learning styles: Chinese students are low in individualism and high in collectivism, and exhibit a strong sense of belonging to a social group and a preference to work together to solve problems (Kennedy, 2002; Nield, 2009; 
Sayers \& Franklin, 2008) Some studies have found that students from a Confucian cultural background have more difficulties in adjusting to the western teaching style than do their western peers. They may adopt a less active learning strategy, and be hesitant about voicing their own opinions in the classroom, while western students are more used to participating actively in class (Auyeung \& Sands, 1996; Duanmu, Li, \& Chen, 2009; Strohschneider \& Guss, 1999; Vita, 2001; Yuen \& Lee, 1994). In addition, Cortazzi and Jin (1997) have shown that Chinese and British students are likely to have different expectations regarding students' and teachers' roles. The Chinese students expect a teacher to be a 'knowledge model' who gives students clear guidance for them to follow, while British teachers act more as facilitators of students' learning by encouraging the learners' own creativity and independence.

However, there are other studies which contradict these findings, suggesting that, contrary to the Chinese student stereotype, Chinese learners have a stronger preference for high-level, meaning-based learning strategies and prefer to avoid rote learning. Kennedy (2002) found that Chinese students can adopt new learning styles when the learning context changes and new learning approaches are needed. Thus, more active and communicative modes of learning may be preferred to a traditional teacher-centered style. According to Durkin (2008), Chinese students approach their learning tasks by adopting a strategic attitude to learning. She found that most East Asian master's students opted for a middle way which synergizes their own cultural approach to critical thinking with western-style critical thinking and debate that are culturally acceptable to them. In this way international students, without being fully acculturated, become 'empathetic insiders', who understand and value the new practices, perceiving them as opportunities for growth and development. Zhang (2013) also found that some Chinese students would choose a middle way to improve their linguistic competence for better academic integration. Instead of approaching native speakers, some Chinese students tried to make friends with other nonChinese students to practice their English and thus gain more confidence in intercultural communication.

\subsection{Chinese Students in Germany}

Given the relatively large number of Chinese students in German HEls, little research has so far been conducted on this group. The existing literature suggests that Chinese students studying in Germany share some problems with those in other countries, such as language issues, financial stress, loneliness, and difficulties in academic integration. Zhu $(2012,2016)$ explored Chinese students' academic adjustment in four phases: pre-departure, initial, developing, and final phase. She found that Chinese students' insufficient preparation (language proficiency and knowledge about German universities) in the pre-departure phase led to difficulties in the initial phase. The students often described their initial experiences as a 'catastrophe', as they were not at all familiar with the academic system in Germany. In the developing phase, Chinese students reported progress in German language and knowledge about German universities, which facilitated their further development. One major challenge in the developing phase was to negotiate the difference in academic expectations between home and host universities. In the final phase, Chinese students showed understanding and appreciation of the expectations at German universities. German language proficiency, academic support, and personal effort together influenced the Chinese students' academic adjustment at German universities.

Moreover, Chinese students studying in Germany with German as the language of instruction reported greater challenges in their academic and social integration (Zhou, 2009). The study by Mao (2011) showed that only half of the international students had studied German before arriving in Germany, while the rest began learning German only on arriving in the country. Consequently, less than one third of Chinese students taking part in the study could report that their proficiency in German was 'good' or 'very good', even though their studies in a German university had already begun (Mao, 2011).

By examining a group of German and a group of Chinese students, Luo and Kück (2011) examined the similarities and differences between these students' learning behaviors and styles. They found that the learning styles of the two groups were amazingly close, as both groups were oriented towards improving their competence and being creative through self-motivation. In addition, they used similar learning methods, such as selflearning and asking questions, and viewed the lecturers as professional and moral examples in academic settings. This demonstrates that cultural differences do not necessarily affect the learning approaches of German and Chinese students.

Guan (2007) compared Chinese and German students' adjustment at the University of Bremen and the University of Göttingen. His research at the University of Bremen the former research suggested that the concept of self played an important role in the adjustment of Chinese students; while at the University of Göttingen he found that when facing difficulties Chinese students used different resources from their German counterparts to deal with the problem. Most Chinese students preferred to turn to books and media instead of talking with native Germans.

In sum, much of the literature on the academic and social integration of international students adopts a cultural perspective focusing on the tensions caused by attempts to cope with cultural differences in a new environment. The research presented in this article was contextualized in different literatures concerning the nature of international students' intercultural communication and intercultural experience. Yet the emphasis was not placed on cultural difference as such, but encompassed various challenges facing the students arising from cultural, peda- 
gogical, linguistic, and institutional perspectives that are also due to the stress of integrating into the larger societal context in addition to the academic context.

Meanwhile, while much attention has been paid to 'cultural difference', less has been paid to the processes of learning, which may be identical across different cultural and academic settings. As the foregoing literature review shows, learning styles may be similar among students from different cultural backgrounds. Strategies for the academic integration of international students may prove to be just as useful when implemented in a brand new academic setting.

For the purposes of the research presented here, the list of relevant questions concerned how students cope with pedagogical and cultural differences, participate in classroom and group learning, interact with teachers and classmates inside and outside class, and how they succeed in their assessments. Social integration refers to a process or state where students establish relatively robust relationships with host-national individuals or communities and take part in diverse social activities. Since the focus of this article is on the academic integration of Chinese students, the examination of their social integration is limited to whether their social integration facilitates their academic integration.

\section{Data and Methods}

Data collected through semi-structured interviews were used to explore the challenges and coping strategies of academic integration among Chinese students in Germany. The author interviewed 26 mainland Chinese tertiary-level degree students in two German universities during spring and summer 2016. Most of the interview questions (except those eliciting demographic information) were open-ended questions enabling students to talk freely and in depth within the range of the research questions, while also allowing flexibility to delve into topics which were not expected at the beginning of the study. All interviews were conducted by the author in Mandarin Chinese to lower the potential barrier of cultural and linguistic difference, while allowing the students to delve deeper into the subject of interest. Most of the interviews were conducted at two German universities. Both universities are large research and teaching HEls offering instruction in the main academic disciplines.

Multiple methods were used to recruit interviewees. First, the author asked the international offices of the two participating universities to send invitations to all mainland Chinese students registered in these universities to participate in the research. The students who volunteered to participate in the research were contacted by email, instant message, or telephone. Second, snowball sampling was used. The research participants were encouraged to invite their friends and other mainland Chinese students who might be interested in joining the research. Third, a research assistant helped to distribute the invitation to interviews through the local Chinese stu- dents' association network. Among the interviewees, 16 were female and 12 male students. All participants were in their twenties with an average age of 24 years for female and 26 for male students. The interviewees came from various academic backgrounds: five were studying natural sciences, four social sciences, three mechanical engineering, three medicine, three computer science, three sports management, two arts and humanities, two German linguistics, one English literature.

Most of the interviewees came from urban middle and upper middle class family backgrounds in China. The group of interviewees included students who had just come to study in Germany for one semester, and those who had come to Germany for more than five years. As the time interval and integration phases of the interviewees were diverse, the author was able to explore which features of academic integration manifest in different phases. Students who had moved to Germany recently had fresh experience of 'culture shock', while the senior students gave lively accounts of how they had managed to overcome academic integration problems in different stages and on their development trajectories. The interviews lasted from one to three hours. The shared language and cultural background facilitated communication between the interviewer and the interviewees. All interviews were recorded and transcribed. The interview data were analyzed using interpretative content analysis; particularly interesting insights were written down during the interview, but most of the analyses were carried out on the basis of the interview transcripts.

In the following section, the challenges and coping strategies of Chinese students' academic integration into Germany will be discussed in detail. In presenting the findings, no such personal data is revealed that would make the interviewees recognizable. The anonymity of respondents is protected, and no real name is disclosed in the article. In the quotations, gender and major subject will serve to characterize the respondents. Citations from the interviews conducted in mandarin Chinese were translated into English by the author.

\section{Findings}

\subsection{Challenges in Academic Integration}

Most of the Chinese students in Germany were studying abroad for the first time in their lives. The challenges they encountered during their academic integration can be categorized into the following themes: language barrier, knowledge gap, cultural difference, and pedagogical difference.

\subsubsection{Language Barrier}

All Chinese students interviewed stressed the importance of German linguistic proficiency in their studies. Indeed, many interviewees had come to study in Germany specifically because they wanted to be fluent in German. 
Some mentioned that they wanted to be fluent in German because they were influenced by German culture and its specifics, such as football or automobiles. Some interviewees estimated that, in addition to achieving academic success in their major subjects, fluency in German was a great added value for their future careers, as the quotation below shows:

It is very common for my generation to go to study in the UK, the cost is higher but you can graduate with your M.A. in one year (after completing the bachelor's degree). However, I chose to study in Germany because there are relatively fewer people speaking German compared to English. When I graduate, I would not only have a diploma from a country with a good reputation for higher education, but also speak two foreign languages. (Female, Medicine)

The language barrier has been mentioned repeatedly in many earlier studies as a major challenge to the integration of international students. However, the extent and severity of the language problems among Chinese students are greater in Germany than in English-speaking countries for three reasons as follows: First, German is the second or third foreign language for most of the Chinese students. While there are international high schools that teach German as a foreign language in China, most of the students study German for one to two years in China or in Germany, and then take the German language test DSH or TestDaf in order to be enrolled in a German HEl. However, even if they succeed in obtaining the language certificate, their linguistic capacity is often far from sufficient to accomplish their academic tasks. The following quotations show that studying in German is not easy for Chinese students:

I think the most difficult challenge in studying here is the language. You don't know what the teacher is talking about, don't know what your classmates are talking about, and when you read the book you want to tear the book apart....You know that when we were in China, we studied English for many years from primary school to university and when we go abroad it is still difficult to use English. Not to even mention mastering German in the short term. Even if we had passed the language test, and had studied the language for two years, when we entered the classroom, we still found ourselves far behind. I think it is necessary for the German universities to reform the DSH test because most foreign students who passed the test are still not fluent enough in German. (Male, Media Studies)

Although I had passed the DSH exam, I still had difficulty adapting to using German language in daily life as well as in academic settings. I found that the German language that people used in daily life was totally different from what we studied in class back in China. The use of vocabulary is different, and people from different regions have different accents. They also tend to speak faster than the listening material we learned from in our classes. It took me about one to two semesters to get used to using German in my daily life. (Male, Sports Management)

Second, the German language taught in China was not the same as the German that the students used in their academic and daily lives. Even for the students of German linguistics it took some time to get used to this:

After coming here (Germany), I found that the things we learned in China were just on paper. I only realized after living in Germany that the (German) language is not spoken in that way (that we learned in China). The cassettes that we listened to in class were very slow, while in reality they speak much faster. When I listened to the German teacher explaining in German, it still took some time before I could truly adapt.... think it took around two months. (Female, German Linguistics)

For some other students not involved in studying German linguistics, it might take up to two years to get used to studying in Germany.

Third, the students who passed the German language tests were adequate in communicating in daily life in German, but their academic vocabulary for their major subjects was still limited. However, in the German-taught classes, German and international students studied together as the teachers did not take them and their special demands into account. This caused problems for some interviewees:

The teachers will teach according to the tempo of German students, without taking into consideration the difficulty of foreigners to follow the class in their second or third foreign language. The pace of the class is often really fast, and there is some vocabulary or even teachers' writing on the blackboard that are incomprehensible for us. (Male, Electrical Engineering)

However, those students who had participated in the Studienkollege before they began their bachelor's studies in Germany, generally had better linguistic proficiency than those who had only taken language classes before entering German universities.

By contrast, Chinese students on English-taught international master's programs seemed to encounter fewer problems. Although they still needed to expand their vocabulary and improve their proficiency in spoken English, the language alone was less of an issue for them compared to those who studied in German.

\subsubsection{Knowledge Gap}

Notably, Chinese students studying their major subjects in either German or in English reported difficulties in understanding the contents of teaching: 
At the beginning of my studies I could understand at most 30 to 40 percent of the teaching. For some classes that were difficult, my understanding was even less than 30 to 40 percent, because even if I had taken the class in Chinese I wouldn't have been able to understand everything. I feel I was not as good as my fellow classmates. (Male, Electrical Engineering)

The difficulty of understanding the content of teaching was often due to gaps in the Chinese students' knowledge background due to differences in curriculum content and structure between German and Chinese universities. Even for the students coming to study in Germany under bilateral agreements the courses they had taken in China were not entirely compatible with the German courses:

What we learn here is very difficult, combined with the abstruse language, it is really torture to understand what the book is trying to say. The classes in which we have background knowledge from classes we took in China were a bit better. But if we hadn't learned something before, we needed to start from the beginning, and this the most difficult part....Once we were required to understand the mechanism of a machine. In China, we had never studied the mechanism behind this machine before. There were at least two to three classes of knowledge gap between our current knowledge reserve and the knowledge required to accomplish this task. We had to work for ten days from 9 a.m. to 11 p.m. in the library with help from others to solve that. It almost drove us crazy. (Male, Machine Mechanics)

The curricula and the focus of studies in China may be so completely different from those in Germany that some students had to study those courses over again. Failing a course was a frustrating experience for many:

Media studies in China generally focuses on practical issues, like how to do an interview and how to produce TV programs. But the courses we took here were more focused on the theoretical side. We have courses in sociology, history, philosophy, literature, etc. It makes me frustrated....It was often that after one semester, I still had no clue what some courses were about. I have never failed classes before, but failing classes here became so common that I became numb...many things I know in Chinese. But I don't know how to express myself in German. Thus, although I have abundant knowledge in my head, I couldn't tell it to others. (Male, Media Studies)

In the first semester, I could understand most of the basic courses. But for some classes that required content-specific background knowledge, such as one class that called Althochdeutsch (Old High German $\mathrm{OHG}$ ), I basically could not understand everything. (Female, German Linguistics)
Surprisingly, failing a lot of classes was a common theme mentioned by several interviewees. Many of them mentioned that they had never failed a class in China, but after they came to Germany, the combined challenge of studying a rigorous module in a foreign language caused them to fail classes more often than before. According to the rules in Germany, if a student fails class three times, he or she will no longer be allowed to study that major in any German university. This increased the stress the Chinese students were enduring.

\subsubsection{Cultural Difference}

Some of the interviewees mentioned that their difficulties in academic integration were caused by differences in cultural practices. This was especially evident among students of humanities and social sciences. In most cases, the students were not able to specify what they meant by 'culture'. This is understandable as cultural phenomena are often immanent, and hidden culture featuring tacit cultural knowledge (such as values and norm systems) is difficult to recognize. The situation was different with visible cultural characteristics. Cultural differences were obvious in cultural studies, for instance in learning experiences which required the students to read literature or review films. One of the interviewees said:

Sometimes in the class, the teacher mentioned a certain author, film director or element of a genre of film and my classmates immediately responded. However, I might not have any clue of what they were referring to, or at least I would not know how to express it in German. Also, the same element, such as a portrait of a dragon in a film, is also quite different in a German film and in a Chinese film. Such cultural differences often cause difficulty for me to follow in class. I found the same difficulty understanding a Chinese film when it was shown in my class. (Female, Film Studies)

In some cases cultural differences were reflected in different ways of thinking and approaching knowledge. One of the senior students compared the German tradition of analytical thinking and debate culture with Chinese traditions as follows:

I think integration is a very bloody word, that after you become integrated, the uncomfortable feeling will always accompany you that on the surface you look like a German, but in fact it is a burden you have to carry with you. Take the critical thinking and debate culture in Germany for example, they like to think this is a constructive way of solving problems.....Germans like to tear the whole thing apart, and analyze where a problem is, then they will find the solution, and tell you point by point they are right. This kind of analytical thinking and debate culture is totally different from the humane way of dealing with conflict as low key as possible in China. It conflicts with the humane 
touch of Chinese society where unnecessary conflicts are usually avoided. (Male, Higher Education)

\subsubsection{Pedagogical Differences}

While the classes in China often took the form of teachercentered lecturing, the learning methods used in German classrooms may be more diverse, including group assignments, classroom discussion, and so on.

Having been provided with answers for many years and having being taught to respect the views of authority, some Chinese students found questioning and challenging peers and lecturers engendered acute discomfort (Wu, 2015). Most of the Chinese students interviewed reported that they would not join in the classroom discussion. The language barrier was the main issue preventing them from active engagement in class. The following students, who had already studied in German HEls for four years, reported still having problems in taking part in classroom discussions:

Until now I can basically know what the teacher was talking about in class, because the teacher must be talking around the main topic. But I have no way to predict what the classmates were about to say. My response reflex is still much slower than the native speakers, and it is not possible for the other students to repeat the content again. That is why I couldn't join in the classroom discussion so well, because I could understand what the teachers were talking about because their expressions are predictable, but following what the classmates were saying is still difficult. (Male, Sociology)

Many other reasons also contributed to a perceived lack of participation of Chinese students in class: First, accustomed to the Chinese teaching and learning environment, some Chinese students felt they were expected to give the 'right answer' to the teachers' questions. They would be reluctant to articulate what came into their minds in class. Second, their silence in class might also be linked to individual personality traits, such as shyness and modesty. They were not accustomed to the western debate culture in class, and would prefer to say nothing. Lastly, a number of students felt a need to know more about the teaching content to provide their own feedback in class, as seen in the following remark:

In the beginning, I would not participate in the classroom discussion because I was really afraid that I would make a mistake if I spoke up in class, and that would make me feel ashamed. So I was basically answering the teacher's questions by heart by myself. Even if sometimes I found the answers from my classmates were wrong, I would still not correct them. (Female, Computer Engineering)

Moreover, examinations in German HEls take different forms from those in China. While in China most exams are written exams, the German exams may also be oral. This form of examination could be quite intimidating for Chinese students, since they had never encountered an oral exam before.

Besides different forms of exams, the final mark usually entails several pieces of essay writing. The students interviewed were still struggling to use German language or, lacking experience in essay writing, might fail to deliver what their teachers were looking for in their work. In addition, the students studying humanities and social sciences were often required to write several essays throughout the whole semester, which could be a daunting and demanding task for the Chinese students. As one of the students said:

There were four modules in our major for each semester. For each of the modules one essay of around 30 pages was required. Together we needed to write about 120 pages for one semester. It took me about one semester to adapt to such intensity of reading and writing. (Female, English Linguistics)

Some of the exams might also be group projects in which the students needed to collaborate to develop a business project or industrial model by themselves. Some of the students interviewed stated that this was the most difficult form of assessment since their knowledge deficit was still too big to fulfill the demand of completing the project by themselves. Coupled with the pressure from working with classmates from other cultural backgrounds this created acute stress for them to cope with. However, it was also a perfect opportunity for them to learn from their peers while doing a group project on their own.

\section{Chinese Students' Academic Integration Strategies}

\subsection{Social Integration and Academic Integration}

The research findings imply that social integration could facilitate Chinese students' academic integration, but those students who were not socially integrated still managed to achieve their academic goals. This result is similar to the findings of the study by Rienties et al. (2012), but additional explanations and nuances can be presented in light of the present study.

Based on the interview data, it can be said that social integration facilitates academic integration mainly through enhancing the students' proficiency in German language and their understanding of German culture. The interviewees explained their experiences as follows:

I intentionally chose to live in a WG (shared dormitory) with five German flat mates. They are very patient in helping me improve my German, and always speak more slowly when talking to me. One of my flat mates said to me, "Why you still say it the wrong way? You have to listen carefully how we say it." I followed 
her advice and now my German is much better than before. (Female, English Linguistics)

Spoken German cannot be learned only through taking classes. You have to get into contact with people. Because different people have different habits of speaking, and use different expressions. Some speak fast, slow, clear, or unclear. You have to get used to different speaking habits of different people. (Female, Computer Science)

While some students were frustrated by their initial failure and communication problems, and would prefer to socialize with only Chinese students, those who managed to step out from the co-national network had benefited from their efforts, which had facilitated their academic integration and enriched their personal lives:

I think one of the major losses of many Chinese after coming here is that they seemed to have lost the capacity to communicate with other people like they did in China. That they were all hiding at home, do not get in touch with the society or the people. I think a social network is not something that you only establish when you need it. Like some of the assignments I need to do for my class, I got help from a friend of a friend. An established network will also help you gain more trust when you are looking for a job. (Female, Mass Media Studies)

However, the students studying very demanding subjects expressed their frustration with the heavy burden of study assignments so that they could not afford to spend as much time on social activities as local or exchange students. For them, social integration might impede academic integration since their study tasks were so burdensome that the students needed to concentrate and devote all their time to their studies. To facilitate better academic integration, the students managed to achieve their study goals by utilizing their social networks with other Chinese students, especially senior ones, and relying on the professionals that they could find in the internet:

We often have group tutor sessions with senior Chinese students. They do not necessarily understand everything, but it is nevertheless helpful for us. (Female, Chemistry)

The findings show that, no matter whether with hostnational, international or co-national students, teaching and learning from others greatly facilitates learning. As one of the Chinese students described his experience:

I often discuss with my classmates. Some knowledge I can read for a day without understanding anything. But discussing with others for one hour can be more efficient than studying by myself for many days. Some knowledge you don't understand but others might have comprehended very well. Just a few examples and you will get the clue....Most of us are helping each other. Nobody can say that I understand everything in this class that I don't need to discuss with others. (Male, Electronics)

Further, the Chinese students rely on online networks with other Chinese to facilitate their better academic integration in Germany. There are various online discussion forums, social media, or websites such as Zhihu ${ }^{1}$ (similar to Quora) that are dedicated to helping netizens solve difficult issues. As in the example mentioned above, one of the students had a pressing task so that it was only with the help of professionals that the students found online through a Chinese website that they managed to complete the assignment.

It can therefore be stated in summary that social integration is helpful for Chinese students' better academic integration, since it enhances their linguistic proficiency in German and enlightens them about German culture, enriches their personal lives, and helps them open doors to new opportunities. However, even without a hostnational network, most Chinese students still managed to achieve their academic goals since they relied on their Chinese peers and senior students, as well as on professionals that they found online. Teaching and learning from others or in a team have proven to be an effective means to achieve better academic integration, no matter if the others are co-national, host-national, or international students.

\subsection{Critical Thinking and Debate Culture}

The Chinese students generally had to go through a phase of gaining a clearer understanding of the learning content, and then to the next stage of critical thinking. The most academically successful students generally developed their capability for critical thinking through their studies. Their better understanding of learning content generally built upon their improved German/English language skills. To compensate for the difficulties in following teaching in class, they would generally invest extra hours at home to digest the material before and after class. After their understanding of the learning material improved through intensive reading, the students would gradually develop critical thinking skills so that they began to form their own judgments about the learning material and express these in their academic work and in class:

Most of the education in China stopped at the phase of understanding. However, they didn't teach the students to ask 'so what?' after they have acquired the knowledge. I think the main difference in German higher education is that they will give a broad perspective of the field by asking you to read different articles

\footnotetext{
${ }^{1}$ Zhihu is an online platform to ask questions and connect with people who contribute unique insights and quality answers.
} 
and book chapters in one semester. After you have established a systematic knowledge of the field, you will need to critically form your own opinion. This is what is lacking in Chinese higher education. And the process of critical and innovative thinking is also the beginning of academic research. I think it will take a long process to adjust to acquire the critical thinking capability. It is an enlightening process, and this process is lacking in Chinese higher education system. (Female, German Linguistics)

However, there were also students who took a negative view of the critical thinking strategy as a learning approach in German universities. One of the interviewees said:

I think the critical thinking I witness in the classes here is quite superficial. Sometimes the students give their opinions and judgments on a certain topic based on their own experience or sometimes based on partial examples from reality. In the classes in China, the teacher told us in the first class: 'I don't expect you to give any opinion on the text for now. You need to fully understand the content first. So I will guide you to read the original text word by word so that you can have a better understanding of the author.' (Female, Sociology)

\subsection{Benefit from Past Learning Experience}

While the challenges posed by studying in a German $\mathrm{HEI}$ were great, some Chinese students could benefit from their previous study experiences in China that smoothed the transition. Their previous education in China had trained them to be resilient and tenacious, so that the challenges they faced in Germany were overcome by a 'can-do spirit'. One interviewee thought that Chinese students have been well trained to cope with learning tasks abroad after years and years of training in a highly competitive education system:

I think my western peers can be easily frustrated since they are more self-centered and used to getting what they want. And when they cannot get what they want, they feel pain. They are the best and brightest students so that they always feel they can control their lives. But for us, we are used to not being able to have full control over our lives. No matter where you are born, after being through a college entrance exam, we have all experienced an abundant amount of failure training. Most of the Chinese students I know, as long as they have the perseverance to proceed, can finish their studies. I have never seen anyone develop psychological issues because of study pressure. (Female, Law)

Unlike many studies that assume rote learning is only a surface learning method adopted strategically by students to pass exams, one of the interviewees said that through memorizing, he managed to achieve a better understanding than before:

There is an old Chinese saying that, read for a thousand times, the meaning will reveal itself. For some of the formulas I don't understand I will try to memorize them. After reciting, reiterating, and comparing with other examples, slowly you will know what it is about. (Male, physics)

Those students with adequate language skills felt that completing the study tasks was no longer a cause of concern. Adopting a strategic approach towards learning, one female student described her experience:

I think an exam is something that the Chinese worry about the least, because we grew up with exams. Although you don't understand one hundred percent of what the teachers were saying in class, there is still hope. They will give us all the PowerPoints to study by ourselves. Even if you still don't understand, you can ask the teacher. (Female, Medicine)

\section{Conclusion}

In conclusion, the difficulty of using a foreign language in academic contexts combined with knowledge gap, pedagogical differences, and cultural differences posed challenges for the Chinese students to achieve academic success. Many students expressed frustration at their lack of linguistic proficiency and adequate general knowledge causing them to fail many classes like never before. However, these challenges also served as a stimulus to come up with new strategies that were more appropriate for their own learning habits and personal dispositions.

Social integration has been proven to facilitate Chinese students' better academic integration by enhancing their linguistic proficiency and improving their cultural awareness. Nevertheless, this is not an absolute prerequisite for better academic integration since the Chinese students without strong social ties with German students also managed to achieve their academic goals by turning to other Chinese for help. The key strategy for studying difficult subjects appeared to be learning in a team with others, regardless of nationality, so that through mutual teaching and learning, the students' study efficiency was greatly enhanced.

The western way of critical thinking and debate was another key barrier that also revealed the underlying cultural difference between east and west. Some interviewees thought that criticism is a missing phenomenon in Chinese education, and that Chinese students only begin to achieve critical awareness after coming to study abroad. However, others doubt the efficiency of putting it into practice prematurely in class when the students have not yet reached advanced comprehension of the learning material. Meanwhile, analytical and critical thinking are claimed to be incompatible with Chinese cul- 
ture, which emphasizes being humane and avoiding unnecessary conflict.

Contrary to the conventional stereotype of Chinese students who only rely on 'learning by rote' and passively listening to teachers in class, this research shows that the students were actually resourceful and innovative in pursing their academic goals through active participation and learning through various sources and platforms. Rote learning was utilized as a pathway to better deep learning. Some interviewees argued that the Chinese students are well-equipped to meet academic challenges in a foreign context since they are used to high pressure exams, and have acquired resilience and tenacity to meet the challenges of academic integration since they have lived through one of the most competitive education systems in the world.

Recognizing the challenges of Chinese students' academic integration and the strategies used to cope with these challenges helps the HEls to adapt to the demands of foreign students. Most German HEls provide orientation lectures and activities to facilitate the integration of international students. However, according to the findings of this study, such orientation activities did not sufficiently address the challenges international students face in adapting to German academic environments. It is recommended that the German HEls organize specific initiatives to address the academic integration of international students, such as mentoring projects that help the students to adapt to their new learning environments more easily. Offering extensive language courses would also be helpful for students using a foreign language in an academic setting. Lastly, academic institutions could organize more social activities with faculty members and students to promote social networking between international students, faculty members, and other fellow students, thereby enhancing international students' class communication, and facilitating their integration into the academic and social environments of the host country.

\section{Acknowledgments}

The study was conducted at Bielefeld University, Germany. It was a part of the Marie Curie project TRANSMIC, funded by the European Union's 7th Framework Programs, coordinated by Maastricht University, which the author gratefully acknowledges. The author would like to thank Pirkko Pitkänen, Virve Kallioniemi-Chambers, and Luuk van der Baaren for providing constructive and useful comments on an earlier version this paper.

\section{Conflict of Interests}

The author declares no conflict of interests.

\section{References}

Aksakal, M., \& Schmidt-Verkerk, K. (2014). Characteristics of temporary transnational migration: The Ger- man case. In Characteristics of temporary transnational migration, collected working papers from the EURA-NET project.

Auyeung, P., \& Sands, J. (1996). A cross cultural study of the learning style of accounting students. Accounting \& Finance, 36(2), 261-274.

Bers, T. H., \& Smith, K. E. (1991). Persistence of community college students: The influence of student intent and academic and social integration. Research in Higher Education, 32(5), 539-556.

Bessey, D. (2012). International student migration to Germany. Empirical Economics, 42(1), 345-361.

Bochner, S., McLeod, B. M., \& Lin, A. (1977a). Friendship patterns of overseas students: A functional model. International Journal of Psychology, 12(4), 277-294.

Bochner, S., McLeod, B. M., \& Lin, A. (1977b). Friendship patterns of overseas students: A functional model. International Journal of Psychology, 12(4), 277-294.

Budyta-Budzyńska, M. (2011). Adaptation, integration, assimilation: An attempt at a theoretical approach. Warsaw Collegium Civitas. Retrieved from http:// migracje.civitas.edu.pl/migracje/images/pdf_eng/ch apter\%203.pdf

Chen, Y., \& Ross, H. (2015). "Creating a home away from home": Chinese undergraduate student enclaves in US higher education. Journal of Current Chinese Affairs, 44(3), 155-181.

Church, A. T. (1982). Sojourner adjustment. Psychological Bulletin, 91(3), 540.

Coles, R., \& Swami, V. (2012). The sociocultural adjustment trajectory of international university students and the role of university structures: A qualitative investigation. Journal of Research in International Education, 11(1), 87-100.

Cortazzi, M., \& Jin, L. (1997). Communication for learning across culture. In D. McNamara \& R. Harris (Eds.), Overseas students in higher education: Issues in teaching and learning (pp. 76-90). London: Routledge.

Duanmu, J., Li, G., \& Chen, W. (2009). Determinants of international students' academic performance: A comparison between chinese and other international students. Journal of Studies in International Education, 14(4), 389-405.

Durkin, K. (2008). The middle way: East Asian master's students' perceptions of critical argumentation in UK universities. Journal of Studies in International Education, 12(1), 38-55.

Furnham, A., \& Alibhai, N. (1985). The friendship networks of foreign students: A replication and extension of the functional model. International Journal of Psychology, 20(3-4), 709-722.

Gu, Q., \& Schweisfurth, M. (2006). Who adapts? beyond cultural models of 'the' Chinese learner. Language, Culture and Curriculum, 19(1), 74-89.

Guan, H. (2007). Anpassung und Integration der chinesischen Studierenden in Deutschland-eine Untersuchung anhand des Beispiels an der Universität Bremen (Doctoral Dissertation). 
Hendrickson, B., Rosen, D., \& Aune, R. K. (2011). An analysis of friendship networks, social connectedness, homesickness, and satisfaction levels of international students. International Journal of Intercultural Relations, 35(3), 281-295.

Kajanus, A. (2016). Chinese student migration, gender and family. Springer.

Kennedy, P. (2002). Learning cultures and learning styles: Myth-understandings about adult (Hong Kong) Chinese learners. International Journal of Lifelong Education, 21(5), 430-445.

Kim, Y. Y. (2000). Becoming intercultural: An integrative theory of communication and cross-cultural adaptation. London: Sage Publications.

Li, A., \& Gasser, M. B. (2005). Predicting Asian international students' sociocultural adjustment: A test of two mediation models. International Journal of Intercultural Relations, 29(5), 561-576.

Luo, X., \& Kück, S. (2011). Gibt es Lernstile, die kulturspezifisch sind? Eine interkulturelle Annährung an das Lernstilkonzept anhand einer vergleichenden Untersuchung am Beispiel deutscher und chinesischer Studenten. Interculture Journal: Online-Zeitschrift Für Interkulturelle Studien, 10(15), 37-62.

Mannan, M. A. (2007). Student attrition and academic and social integration: Application of Tinto's model at the university of Papua New Guinea. Higher Education, 53(2), 147-165.

Mao, X. (2011). Die soziale und wirtschaftliche Llage der chinesischen Studierenden in Berlin 2010. GRIN Verlag.

Maundeni, T. (2001). The role of social networks in the adjustment of African students to British society: Students' perceptions. Race, Ethnicity and Education, 4(3), 253-276.

Ministry of Education of P. R. of China. (2016). Trend of Chinese students studying abroad in 2015. Retrieved from http://www.moe.gov.cn/jyb_xwfb/gzdt _gzdt/s5987/201603/t20160316_233837.html

Nield, K. (2009). The problems of applying labels of learning style to national cultures. International Journal of Learning, 16(7), 425-434.

Rienties, B., Beausaert, S., Grohnert, T., Niemantsverdriet, S., \& Kommers, P. (2012). Understanding academic performance of international students: The role of ethnicity, academic and social integration. Higher Education, 63(6), 685-700.

Sayers, J., \& Franklin, T. (2008). Culture shock! Cultural issues in a tertiary course using reflective techniques. Reflective Practice, 9(1), 79-88.

Severiens, S. E., \& Schmidt, H. G. (2009). Academic and social integration and study progress in problem based learning. Higher Education, 58(1), 59-69.

Smith, C. S. (2017). Canada beckons international students with a path to citizenship. The New York Times.

Strohschneider, S., \& Guss, D. (1999). The fate of the moros: A cross-cultural exploration of strategies in complex and dynamic decision making. International Journal of Psychology, 34(4), 235-252.

Süssmuth, R. (2009). The future of migration and integration policy in Germany. Migration Policy Institute, $1-23$.

Terenzini, P. T., \& Pascarella, E. T. (1977). Voluntary freshman attrition and patterns of social and academic integration in a university: A test of a conceptual model. Research in Higher Education, 6(1), 25-43.

Tinto, V. (1975). Dropout from higher education: A theoretical synthesis of recent research. Review of Educational Research, 45(1), 89-125.

Tinto, V. (1997). Classrooms as communities: Exploring the educational character of student persistence. Journal of Higher Education, 599-623.

Tremblay, K. (2005). Academic mobility and immigration. Journal of Studies in International Education, 9(3), 196-228.

UNESCO Institute for Statistics. (2016). Global flow of tertiary-level students. Retrieved from http:// uis.unesco.org/en/uis-student-flow

Vita, G. D. (2001). Learning styles, culture and inclusive instruction in the multicultural classroom: A business and management perspective. Innovation in Education and Teaching International, 38(2), 165-174.

Wissenschaft Weltoffen. (2016). Wissenschaft weltoffen kompakt: Facts and figures on the international nature of studies and research in Germany. Deutsche Akademische Austauschdienst (DAAD) und Deutsche Zentrum für Hochschul- und Wissenschaftsforschung (DZHW GmbH). Retrieved from http://www.wissenschaftweltoffen.de/publikation/ wiwe_2016_verlinkt.pdf

Wu, Q. (2015). Re-examining the "Chinese learner": A case study of mainland chinese students' learning experiences at british universities. Higher Education, 70(4), 753-766.

Yuen, C., \& Lee, S. N. (1994). Applicability of the learning style inventory in an Asian context and its predictive value. Educational and Psychological Measurement, 54(2), 541-549.

Zhang, H. (2013). Academic adaptation and crosscultural learning experiences of chinese students at American universities: A narrative inquiry (Doctoral Dissertation).

Zhou, J. (2009). Zwischen "elite von Morgen" und liuxue-laji ("Müllstudenten"): Chinesische studenten in Deutschland (Doctoral Dissertation). Retrieved from https://portal.dnb.de/opac.htm?method=simpleSea rch\&cqlMode=true\&query=idn\%3D1000848345

Zhu, J. (2012). Academic adjustment of Chinese students at German universities (Doctoral Dissertation).

Zhu, J. (2016). Approaching the end: Appreciating the German learning environment. In Chinese overseas students and intercultural learning environments ( $\mathrm{pp}$. 175-186) Springer. 


\section{About the Author}

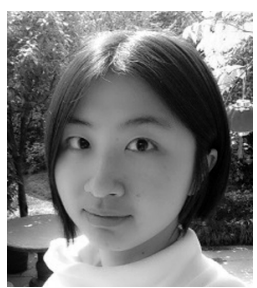

Hanwei Li is a Marie Curie PhD researcher working on a European Commission funded project entitled Transnational Migration, Citizenship and the Circulation of Rights and Responsibilities (TRANSMIC). She is currently pursuing a joint degree of PhD in Education at the University of Tampere and PhD in Sociology at the University of Bielefeld. Her research interests include: Asia-Europe student mobility, academic integration, socio-cultural integration, internationalization of higher education transnationalism, investment migration, and citizenship. 